\title{
Conflict Resolution Strategies Observed During Discussions among Students with Different Personalities
}

\author{
Siew Fong Lin (Corresponding author) \\ Faculty of Social Science, Arts and Humanities \\ Tunku Abdul Rahman University College \\ P.O Box 10979, 50932 Kuala Lumpur, Malaysia \\ Tel: 603-4145-0123Ｅ-mail: linsf@acd.tarc.edu.my
}

Received: July 21, 2017

doi:10.5296/gjes.v3i2.
Accepted: August 10, 2017

Published: August 25, 2017

URL: https://doi.org/10.5296/gjes.v3i2.

\begin{abstract}
The aim of this study is to obtain insight on conflict resolution strategies during collaborative writing among students with different personality profiles categorised under Leonard Personality Inventory (LPI) in Malaysia. A case study group consisting of five Diploma in Mass Communication students were observed. The research instruments used were video recordings, interviews, diary entries and observations. The findings in this study showed the use of conflict resolution strategies in reducing conflict in the course of collaboration. Consequently, there were mixed results on the group dynamics. The methods in conflict resolution could be divided into collectivist and individualistic approaches. The former were using humour to diffuse tension, filtering ideas and diverting attention from conflict by voluntary involvement in performing sub-tasks. However, the latter were the leader being abrasive towards group members and the group members ignoring leader's guidance. In addition, it was obvious that some participants behaved according to their personalities consistently while some placed priority on their roles played in the group. It is recommended that self-reflection be encouraged to improve collaboration and guidance on facilitation of groups be provided to group leaders prior to their collaboration.
\end{abstract}

Keywords: Collaborative writing, Leonard personality inventory, Conflict, Conflict resolution strategies, Group dynamics, Task performance 


\section{Introduction}

Principles in Sociocultural Theory (Vygotsky, 1978) are highlighted in groupwork. It is perceived that learning is enhanced in social settings through the use of interactions. Collaborative activities enable scaffolding to occur through which knowledge sharing helps in task performance (Ohta, 2001).

There are advantages in using collaborative work. It can result in improvements in writing such as being grammatically accurate (Storch, 1999; 2005) and making it possible for peers to edit one's work (Elola \& Oskoz, 2010). On the other hand, there are challenges faced by students involved in groupwork, too. Feedback provided on work may adversely affect relationships (Elola \& Oskoz, 2010; Shehadeh, 2011) and success during collaboration among students when paired or placed in groups may not be guaranteed (Storch, 2001 \& 2002; Watanabe \& Swain, 2007).

According to Moran and John-Steiner (2004), they explain that collaborators possess differing perceptions, talents, conceptualisations, working styles, personalities, resources and desires. The outcomes from collaboration are very much influenced by these differences among individuals. Therefore, in this study, personality which is one of the dissimilar attributes among learners is given much prominence. Personality is defined as "individual differences in characteristic patterns of thinking, feeling and behaving" (American Psychology Association, 2016). Two areas observed in the study of personality are understanding individual differences in personality characteristics and understanding how the various parts of a person become whole. (American Psychology Association, 2016).

LEONARD Personality Inventory (LPI) has 100 items. They were used to assess behavioural styles of the participants in this study. LPI was developed by Professor Leonard Yong (1999). The inventory is used to identify emotional orientations based on five dimensions of personality which are Openness, Neutral, Analytical, Relational and Decisive.

Yong (1999) has provided descriptions of the characteristics of individuals belonging to each dimension. Individuals with Openness dimension manage situations with new and unique methods but are easily misunderstood by others due to their impulsive behaviour. People with Neutral dimension are introverts, patient and loyal but lack confidence. Analytical individuals are perfectionists, meticulous but sensitive in nature. Those belonging to Relational dimension are sociable, extroverts and optimistic but disorganised. Decisive people are described as driven, result-oriented and risk-takers but strong headed. In addition, Yong (2012) has provided a total of 26 Personality Profiles derived from research findings on LPI. They are Creative Imaginator, Neutral Expert, Analytical Thinker, Relational Interactor, Decisive Decision-Maker, Error Buster, Exhorter, Helpful Encourager, Implementer, Accomplisher, Assessor, Creative Expert, Creative Thinker, Creative Relator, Creative Decision-Maker, Creative Error Buster, Creative Exhorter, Creative Encourager, Innovator, Creative Accomplisher, Creative Assessor, Amiable Adaptor, Resourceful Strategist, Persuasive Decision Maker, Energetic Strategist and Versatile. 


\section{Literature Review}

Personality differences among learners may result in conflict when they collaborate with one another. According to Fisher and Ury (1981), conflict may be unpreventable when more than one parties are involved in the communication process. Conflict has a significant impact on learners during collaborative efforts.

Productive conflict promotes group success because group members are reminded not to focus on others' weaknesses (Dale, 1994). Consequently, positive group dynamics are created. In addition, Johnson (1981) who studied peer interactions observes that conflict can be used to achieve goals. Controversy can increase learning for it allows learners to be exposed to diverse perspectives through their sharing of knowledge.

Furthermore, students are prepared for the "real world" in which division of work may not be fairly distributed (Speck, 2002). They learn how to handle such situations at their future workplaces when they had faced similar circumstances during collaborative work as students. This can be explained by them being equipped with important skills they had gained from their prior experiences working with others (Price \& Warner, 2005).

Conflict resolution styles to be adopted differ from individual to individual. A model advocated by Kilmann and Thomas (1977) which is based on Blake and Mouton (1964) is commonly used. It focuses on two premises which are assertiveness and cooperativeness. The combination of the premises results in five conflicting styles which are avoidance, competition, accommodation, compromise and collaboration.

There are various past studies conducted on investigating conflict resolution styles. It is found that cultural orientation has a strong influence on the styles adopted. Collectivist approach focuses on non-confrontational strategies which promote harmony while individualistic method values independence in the group process. Triandis (1995) believes there are benefits and challenges in both collectivist and individualistic culture. The advantages of collectivist culture are increasing high morality and reducing social problems while the disadvantages are lacking creativity and reducing rights of members. However, the benefits of individualistic culture are promoting democracy and creativity but can result in members feeling ostracised and narcissistic.

Cultural orientation is found to influence conflict management in groups. Souren, Samarah, Seetharaman and Mykytyn (2004) in their study on groupware-supported, culturally homogenous and heterogeneous virtual teams discovered that collectivist orientations enhance the level of collaborative conflict management style. In addition, Jwa (2016) who conducted a study on communication among Korean, Malaysian and Japanese students who were enrolled in an online synchronous class identified three types of facework which were self-mocking humour, group embarrassment and efforts to create group cohesion. Furthermore, a study which focused on the mediator role of conflict resolution strategies in the relationship between regulatory foci and friendship satisfaction among Chinese adolescents revealed that the problem-solving process mediated between promotion focus and friendship satisfaction while 
conflict mediated the relationship between prevention focus and friendship satisfaction (Gao, Bian, Liu, He, \& Oei, 2017).

There are past studies which focus on the manner of communication when resolving differences among individuals. Shin, Liu, Jang, and Bente (2017) discovered that in the process of conflict resolution using video chat encounters and face-to-face approaches, there was less emotional arousal during video interactions than face-to-face communication and a lack of physical co-presence may be positive for mediation. Therefore, positive results during mediation can be achieved when certain conditions are fulfilled. In addition, a research studying moderating effects of Generations $\mathrm{X}$ and $\mathrm{Y}$ on the relationship between personality and conflict management approaches revealed that training in conflict resolution and communication skills are necessary to increase co-operation between the different generations at the workplace (Canaan Messarra, Karkoulian, \& El-Kassar, 2016). It is also crucial to include the component of emotion management when training mediators to be involved in conflict resolution due to the significance of emotional learning (Ibarrola-Garcia, Iriarte, \& Aznarez-Sanado, 2017).

\section{Methodology}

A case study group consisting of five Diploma in Mass Communication students from a private university-college was formed for this study. The female participants were Moira, Sandy and Tina. Albert and Will were the male participants in the study.

A group writing task in the form of producing a script of about 2000 words was given to the participants. The script should consist of three acts. After the participants had learned the different types of drama during their lecture, they were provided with the opportunity to select either one or even more genres for their script.

The participants had a total of five sessions of collaborative writing to perform the task. Each session was ninety minutes long. The sessions were video recorded. In addition, the participants were interviewed and produced journals detailing their experiences during their collaboration.

\section{Findings}

This section is divided into two sections. They are information on the participants' personality profiles and conflict resolution approaches adopted by the participants during collaboration.

\subsection{Participants' Personality Profiles}

The participants in this study completed the LPI questionnaire to discover their respective personality profiles. Albert was a Creative Relator while Moira and Sandy were Helpful Encouragers. In addition, Will was an Exhorter and Tina was a Creative Expert.

\subsection{Conflict Resolution Strategies}

The findings in this study showed there were conflict resolution strategies used in the course of collaboration. They had mixed results on the overall group dynamics. The methods in 
conflict resolution which adopted the collectivist approach were non-confrontational. They comprised using humour to diffuse tension, filtering ideas and diverting attention from conflict by voluntary involvement in performing sub-tasks. However, strategies which were influenced by individualistic approach were confrontational. They consisted of leader being abrasive towards group members and group members ignoring leader's guidance.

\subsubsection{Methods which Adopted Collectivist Approach}

\subsubsection{Using Humour to Diffuse Tension}

A common strategy used by the group members when diffusing tension during collaboration was humour. Humour has been found to be a useful tool in reducing tension (O'Quin \& Aronoff, 1981). It was initiated by Albert in many encounters. It could be due to his personality profile as being in the Creative Relater category who has been described as interactive and enjoys being in the centre of attention (Yong, 2012). He did not want the arguments to develop into quarrels which might adversely affect the group communication and dynamics.

The use of make-up to prepare the group members before performing in the play was suggested by Moira in the first collaborative writing session. However, Sandy opposed the idea. Albert quickly made a joke saying that he would use ice-cream instead. Consequently, the group laughed over it and progressed to the discussion on the type of genre to use for the play instead.

The group used humour to diffuse tension, too, when deciding if they were to perform a musical play. Will persuaded Sandy to sing in the play and she disagreed with him. He even elaborated by saying that everyone had the ability to sing while she continually refused to do it. Albert jokingly advised her to sing from her heart, stating that her singing would move many hearts and patting Will's chest repeatedly. As a result, the group laughed over the joke and proceeded to continue discussing on the characters in the play.

\subsubsection{Filtering Ideas}

One of the conflict resolution approaches used by Sandy as the leader was to filter information presented by her group. She vetted through the ideas provided during the discussions. They consisted of reminding Albert that their play could not focus on events which occurred for two months, seeking for names of characters created, summarising from the lengthy discussions the genres the group was using which were tragedy and comedy and making a distinction between brand of clothes and types of clothes used for the play. Sandy expressed her dissatisfaction with her group's progress through the interviews and diary entries.

Sandy's efforts produced mixed results during the collaborative sessions. The positive outcome was the group could have smooth and organised interactions with each other in some encounters. However, in many situations, Albert and Will failed to follow her guidance but changed topics of discussions according to their wishes and challenged her authority continually. It was discovered through the interviews and diary entries that Albert seemed 
satisfied with the collaboration because he had the opportunity to interact while Will was happy with his group until the second last session when he voiced out his concern over the lack of progress in their work.

\subsubsection{Methods which Adopted Individualistic Approach}

\subsubsection{Diverting Attention from Conflict by Voluntary Involvement in Performing Sub-Tasks}

An interesting conflict resolution strategy adopted in the course of collaboration was diversion. It was observed that Moira was disturbed by Sandy's abrasive behaviour. Both Moira and Sandy were categorised as being in the Helpful Encourager personality profile and described as being focussed on maintaining harmony. However, only Moira was seeking to promote peace while Sandy placed priority over her role as a leader in ensuring that her group completed the task successfully by being forceful.

It was observed that Sandy took over Moira's task of recording down points discussed during the discussions by force when the former noticed the latter's lack of concentration on the discussions. Sandy began to write furiously and angrily as she facilitated the interactions using a harsh tone. Consequently, Moira proceeded to gently pull the paper from Sandy when she was reprimanding Albert and Will over their concerted effort in behaving in a lackadaisical manner. It resulted in Sandy being distracted from her action and allowing Moira to continue writing for her group. Moira expressed through her interviews and diary entries of her discomfort of the tension existing and was relieved when it eventually discontinued. It was clear that she did not want her group to be working in a state of disharmony.

\subsubsection{Being Abrasive towards Group Members}

The second conflict resolution strategy used by Sandy as the leader was being abrasive towards her group. She initially used the first method which was filtering ideas in hoping her group members would follow her instructions. When they failed to allow her to facilitate their discussions, she decided to become harsh with them in using verbal and non-verbal language.

Sandy's abrasive manner could be observed from her verbal and non-verbal behaviour. Her tone was sarcastic and she openly challenged her group members who refused to follow her guidance. Similarly, she treated her group members who did not answer her leading questions in this manner.

Furthermore, she even snatched a paper on which Moira was initially writing on from her when she observed that she was not attentive in recording points which were discussed. Sandy eventually continued writing the script as the interactions continued. It was the leader's last resort in ensuring that the task was performed successfully despite having her to be directly involved in monitoring the situations. It was found from the interviews and diary entries that Sandy was extremely frustrated with her group's lack of seriousness in the task while Moira expressed her discomfort in being involved in the challenging group collaboration.

Sandy despite being categorised as belonging to the Helpful Encourager personality profile 
was not prioritising in being harmonious in the group. She was attempting to maintain peace initially but decided to change her strategy of handling her group as the collaboration progressed. Consequently, she decided to use a harsh manner in maintaining control.

\subsubsection{Ignoring Leader's Instructions}

An obvious strategy used by the group in managing conflict was ignoring their leader, Sandy. Will and Albert decided to side-track the discussions by openly challenging Sandy through their verbal and non-verbal behaviour. It could be their response in confronting Sandy's harsh manner in facilitating the group. Albert despite being a Creative Relater who is described as sociable (Yong, 2012) did not emphasise on being so but decided to be confrontational towards Sandy. Will who is an Exhorter and has been described as confident and persuasive (Yong, 2012) was shown to be determined in presenting his views.

The first encounter was when Sandy asked her group to make decisions on social media, vehicles and clothes to be used in the play. Albert who arrived late for the session stated that Giordano should be used. Sandy corrected him impatiently by saying that it was a brand of clothes and not type of clothes to be worn. When Sandy proceeded to seek decisions to be made on accessories, lifestyle and food to be used in their performance, Albert retorted by challenging her that all of them were the same.

When Sandy guided her group in making a decision on whom to play the role of the father, Will and Albert decided to divert attention from it. Both of them challenged her by dismissing it and explaining that it was unimportant. In addition, they added that they could decide on it at a later time. As a result, Sandy had to introduce a new topic of discussion which was deciding on the murderer of the father instead.

\section{Conclusion}

There were a few conflict resolution strategies observed in this study during collaborative writing. The methods in conflict resolution were using humour to diffuse tension, filtering ideas, diverting attention from conflict by voluntary involvement in performing sub-tasks, leader being abrasive towards group members, and ignoring leader's guidance. They had mixed results on the overall group dynamics and task performance.

There were positive and negative effects of the conflict resolution methods used by the group. The use of humour and filtering of ideas resulted in the group having an interesting time during discussions and assisting in performing the task successfully. However, the leader's abrasiveness and the response of the group towards her by ignoring her created tension and frustrations among the group members. In addition, it was found that some of the group members did not behave exactly according to the characteristics of their personality profiles but emphasised on playing their roles in the group in order to complete their writing task.

Therefore, it is suggested that group members be encouraged to reflect on their interactions regularly. It will help them to be more aware of how their contributions affect group dynamics. Furthermore, they can help to improve on their communication with others during collaboration. This is supported by findings from a study conducted by Higgins, Flower and 


\section{MInstitute Macrothink $_{\text {Int }}$}

Global Journal of Educational Studies ISSN 2377-3936 2017, Vol. 3, No. 2

Petraglia (1992) on collaborative writing which highlighted the importance of critical reflection in the process of effective planning.

In addition, it is recommended that leaders of groups be provided with guidance in facilitating their groups. Hilgers (1987) opined that collaborative skills should be taught to help improve the quality of collaboration. When collaborators are equipped with these skills, a positive environment for collaboration can be created. It was obvious from the findings in this study in which negative group dynamics resulted from group members who were not prepared to work well together.

\section{Acknowledgements}

The use of LEONARD Personality Inventory (LPI) questionnaire is permitted by Professor Dr. Leonard Yong and special thanks to him for allowing participants in this study to answer the questionnaire online.

\section{References}

American Psychology Association. (2016, June 23). Retrieved from http://www.apa.org/topics/personality/

Blake, R. R., \& Mouton, J. S. (1964). The managerial grid: Key orientations for achieving production through people. Houston, TX: Gulf.

Canaan, M. L., Karkoulian, S., \& El-Kassar, A. N. (2016). Conflict resolution styles and personality: The moderating effect of generation $\mathrm{X}$ and $\mathrm{Y}$ in a non-Western context. International Journal of Productivity and Performance Management, 65(6), 792-810. https://doi.org/10.1108/IJPPM-01-2016-0014

Dale, H. (1994). Collaborative Writing Interactions in One Ninth-Grade Classroom. Journal of Educational Research. 87(6), 334-44. https://doi.org/10.1080/00220671.1994.9941264

Donato, R. (1994). Collective scaffolding in second language learning. In J. P. Lantolf, \& G. Appel (Eds.), Vygotskian approaches to second language research (pp. 33-56). Norwood, NJ: Ablex.

Elola, I., \& Oskoz, A. (2010). Collaborative writing: Fostering foreign language and writing conventions development. Language Learning \& Technology, 14(3), 51-71.

Fisher, R., \& Ury, W. (1981). Getting to yes: Negotiating agreement without giving in. New York: Penguin Books.

Gao, Q., Bian, R., Liu, R. D., He, Y., \& Oei, T. P. (2017). Conflict resolution in Chinese adolescents' friendship: Links with regulatory focus and friendship satisfaction. Journal of Psychology: Interdisciplinary and Applied, 151(3), 268-281. https://doi.org/10.1080/00223980.2016.1270887

Higgins, L., Flower, L., \& Petraglia, J. (1992). Planning text together: The role of critical reflection in student collaboration. Written Communication, 9(1), 48-84. https://doi.org/10.1177/0741088392009001002 


\section{MInstitute Macrothink $_{\text {Int }}$}

Global Journal of Educational Studies ISSN 2377-3936 2017, Vol. 3, No. 2

Hilgers, T. L. (1987). Young Writers Facing a New Collaborative Writing Task. Journal of Research in Childhood Education, 2(2), 108-16. https://doi.org/10.1080/02568548709594927

Ibarrola-García, S., Iriarte, C., \& Aznárez-Sanado, M. (2017). Self-awareness emotional learning during mediation procedures in the school context. Electronic Journal of Research in Educational Psychology, 15(1), 75-104. https://doi.org/10.14204/ejrep.41.15175

Johnson, D. W. (1981). Student-Student Interaction: The Neglected Variable in Education. Educational Researcher, 10(1), 5-10. https://doi.org/10.3102/0013189X010001005

Jwa, S. (2016). Facework among L2 speakers: A close look at intercultural communication. Journal of Multilingual and Multicultural Development, 1-13. https://doi.org/10.1080/01434632.2016.1212864

Kilmann, R. H., \& Thomas, K. W. (1977). Developing a forced-choice measure of conflict handling behavior: The "mode" instrument. Educational and Psychology Measurement, 37, 309-325. https://doi.org/10.1177/001316447703700204

Moran, S., \& John-Steiner, V. (2004). How collaboration in creative work impacts identity and motivation. In D. Miell, \& K. Littleton (Eds.), Collaborative creativity, contemporary perspectives (pp. 11-25). London: Free Associate Books.

O'Quin, K., \& Aronoff, J. (1981). Humour as a technique of social influence. Social Psychology Quarterly, 44, 349-357. https://doi.org/10.2307/3033903

Ohta, A. S. (2001). Second language acquisition processes in the classroom: Learning Japanese. Mahwah, NJ: Lawrence Erlbaum.

Price, M., \& Warner, A. B. (Dec. 2005). What You See Is (Not) What You Get: Collaborative Composing in Visual Space. Across the Disciplines. Retrieved Nov. 1, 2007, from http://wac.colostate.edu/atd/visual/price_warner.cfm

Shehadeh, A. (2011). Effects and student perceptions of collaborative writing in L2. Journal of Second Language Writing, 20(4), 286-305. https://doi.org/10.1016/j.jslw.2011.05.010

Shin, S. Y., Liu, W. R., Jang, J. W. B., \& Bente, G. (2017). The benefits of distance and mediation: How people react to conflicts in video chat vs. FtF. Computers in Human Behaviour, 73, 1-8. https://doi.org/10.1016/j.chb.2017.03.022

Souren, P., Samarah, I. M., Seetharaman, P., \& Mykytyn, P. P. JR. (2004). An Empirical Investigation of Collaborative Conflict Management Style in Group Support System-Based Global Virtual Teams. Journal of Management Information Systems, 21(3), 185-222. http://dx.doi.org/10.1080/07421222.2004.11045809

Speck, B. W. (2002). Facilitating Students' Collaborative Writing. San Francisco: Jossey-Bass.

Storch, N. (1999). Are two heads better than one? Pair work and grammatical accuracy. System, 27(3), 363-374. https://doi.org/10.1016/S0346-251X(99)00031-7 


\section{Macrothink}

Global Journal of Educational Studies

ISSN 2377-3936

2017, Vol. 3, No. 2

Storch, N. (2001). How collaborative is pair work? ESL tertiary students composing in pairs. Language Teaching Research, 5, 29-53. https://doi.org/10.1177/136216880100500103

Storch, N. (2002). Patterns of interaction in ESL pair work. Language Learning, 52(1), 119-158. https://doi.org/10.1111/1467-9922.00179

Storch, N. (2005). Collaborative writing: Product, process, and students' reflections. Journal of Second Language Writing, 14, 153-173. https://doi.org/10.1016/j.jslw.2005.05.002

Triandis, H. C. (1995). Individualism and collectivism. Westview: Boulder.

Vygotsky, L. S. (1978). Mind in Society: The development of higher psychological processes. Cambridge, MA: Harvard University Press.

Watanabe, Y., \& Swain, M. (2007). Effects of proficiency differences and patterns of pair interaction on second language learning: Collaborative dialogue between adult ESL learners. Language Teaching Research, 11, 121-142. https://doi.org/10.1177/136216880607074599

Yong, L. M. S. (1999). The LEONARD Personality Inventory. Petaling Jaya: Nemo Marketing.

Yong, L. M. S. (2012). Emotional Excellence in the Workplace - LEONARD Personality Inventory (LPI) Personality Profiling. Kuala Lumpur: LEONARD Personality Incorporated.

\section{Copyright Disclaimer}

Copyright for this article is retained by the author(s), with first publication rights granted to the journal.

This is an open-access article distributed under the terms and conditions of the Creative Commons Attribution license (http://creativecommons.org/licenses/by/3.0/). 